\title{
Challenges Confronting Scientific Research: A Systematic Review
}

\author{
Dr. Abdullah Aedh1, Dr. Nahid Khalil Elfaki² \\ 1,2Assistant professor \\ ${ }^{1}$ College of Medicine, Najran University- KSA, Najran, Saudi Arabia \\ ${ }^{2}$ College of Nursing, Najran University- KSA, Najran, Saudi Arabia
}

\begin{abstract}
How to cite this paper: Dr. Abdullah Aedh | Dr. Nahid Khalil Elfaki "Challenges Confronting Scientific Research: A Systematic Review" Published in International Journal of Trend in Scientific Research and Development (ijtsrd), ISSN: 24566470, Volume-3 | Issue-4, June 2019, pp.1-3, URL: https://www.ijtsrd. com/papers/ijtsrd
\end{abstract} 23578.pdf

Copyright (C) 2019 by author(s) and International Journal of Trend in Scientific Research and Development Journal. This is an Open Access article distributed under the terms of the Creative Commons

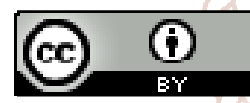
Attribution License (CC BY 4.0) (http://creativecommons.org/licenses/ by/4.0)

\section{ABSTRACT}

Background: The basis of scientific research is gaining knowledge and in its use, often to improve the communities and the world. Therefore, high quality research can play a critical and important role in communities' development. The main objective of this survey was to explore the existing challenges that facing scientific research as well as to propose some suggestions that can help to overcome these obstacles.

Methodology: It was a literature review, in which systematic reviews of published studies and meta-analysis were utilized. Data was collected from different sources nationally and internationally. A total of 181 articles related to the review title were accessed. After secondary reviewing, 138 articles had been excluded either by their titles which were found to be not related directly to our topic, or because the abstracts or full-text were considering an individual predictors. The remaining 43 full-text articles had been accessed and evaluated for eligibility based on predetermined inclusion and exclusion criteria. Therefore, only 16 studies were included in the systematic review and metaanalysis during the period from September, 2018 to January 2019. The databases that used were PubMed, Google Scholar, SAGE and Academic Search Complete Magazines and Journals (EBSCO).

Results: Out of forty three articles that had been reviewed, sixteen studies were included in the meta-analysis. This review revealed that the most major challenges that face research had been grouped into four main groups. These groups include scarcity of resources and funding, lack of motivation, lack of training, guidance and supervision, organizational obstacles and difficulties when collecting data.

Conclusion: Considering the result of the research, the major challenges that facing research include scarcity of resources and funding, lack of motivation, lack of training, guidance and supervision, organizational obstacles and difficulties for obtaining data, which is accompanied by low demand for research by stakeholders. Research capacity building courses, collaboration and networking opportunities are urgently needed. Additionally, it was suggested that the two key ways to encourage strong research studies would involve rethinking the rewards system and building more transparency into the research process beside getting ways to increase grants for running the costs. Motivation and effective learning and training are also to be considered.

KEYWORDS: Scientific research, challenges, literature review

\section{Background}

Research is the product of curiosity. Without research, our demands would go completely unrecognized. Since World War 2, there has been intense activities regarding developing research, and in particularly the medical or health research. Investment in scientific research requires the availability of a number of essential elements, including human resources, universities and research centers, finance, the structure of the labor market, in addition to the protection of intellectual property rights and the general investment climate. ${ }^{1}$

The basic scientific research aims at reaching new and specific solutions to a particular issue or developing new products and methods through introduction of general principles of new knowledge or ideas. ${ }^{2}$ Despite challenges facing research's scientists, the pursuit of knowledge 
through scientific endeavor can be a rewarding career. ${ }^{3}$ Although, sometimes both governments and individuals are pessimistic when they see how difficult it is to make much of an impression on the problems, this should not blind us from the fact that a great deal has been achieved.

Nevertheless, a very large gap between desirability and achievement clearly exists, and the question is what can be done to close this gap?

\section{Methodology Searching strategies}

This survey was a literature review that done through a qualitative research method, in which systematic reviews of published studies and meta-analysis were utilized. Data was collected from different sources nationally and internationally. A total of 181 articles related to the review title were accessed. After secondary reviewing, 138 articles had been excluded either by their titles which were found to be not related directly to our topic, or the abstracts or fulltext were considering an individual predictors. The remaining forty three full-text articles had been accessed and evaluated for eligibility based on predetermined inclusion and exclusion criteria. Therefore, only sixteen studies were included in the systematic review and metaanalysis during the period from September, 2018 to January 2019. The databases that used were PubMed, Google Scholar, SAGE and Academic Search Complete Magazines and Journals (EBSCO). The used search key terms were challenges facing research, scientific research.

\section{Study selection}

Potentially eligible studies for the current systematic review and meta-analysis were selected in three stages: the titles alone, followed by abstracts and finally the full-text articles based on the following inclusion and exclusion criteria:

\section{Inclusion and exclusion criteria for data collection} The inclusion criteria:

$>$ Articles written in English language.

$>$ Articles that published in peer-reviewed journals

$>$ Articles of published date of the year 2000 to date.

$>$ Articles that are relevant to this article topic.

\section{The exclusion criteria:}

$>$ Articles that written in other languages rather than English language.

$>$ Articles which were not fully accessible.

$>$ Articles that published before the year 2000 .

$>$ Irrelevant articles to this article topic.

\section{Results}

Upon initial screening, a total of 181 articles related to the review title were accessed. After secondary reviewing, 138 articles had been excluded either by their titles which were found to be not related directly to our topic, or the abstracts or full-text were considering an individual predictors. The remaining forty three full-text articles had been accessed and evaluated for eligibility based on predetermined inclusion and exclusion criteria. Therefore, only sixteen studies were included in the systematic review and metaanalysis. Based on the information from these articles, the current study's results revealed that the major challenges that had been concluded in this survey had been grouped into four major groups as follow:
Scarcity of resources and funding, lack of motivation, lack of training, guidance and supervision, organizational obstacles and difficulties for obtaining data.

\section{Resources and research facilities problems}

The demand for resources is far exceeds the funds which is crucial for research. Considering international aspects, it is clear that big science and projects are becoming too costly for countries, accompanied by low demand for research by policy-makers. First of all, systematic reviews require access to a wide range of databases and peer-reviewed journals, which can be problematic and very expensive. It is well known that some publishers put their journals behind pricey pay-walls. Additionally, money is needed too to run studies, in terms of subsidizing lab equipment, for paying research assistants and even for their own expenses. Moreover, after a study has been funded, conducted and peer-reviewed, there is still the question of publishing and getting it out so that others can read and understand its results. Declining investment in research has been cited as a reason for deteriorating research quality. ${ }^{4}$

\section{Lack of motivation and incentives}

This survey highlighted the challenges related to motivation and incentives as one of the major challenges that encounter research. Researchers argue that most of the time work demand does not give room for research. They just admire it but do not have enough time for it. This makes them less supportive to new ideas and thus less encouraged for conducting research.

\section{Lack of training, guidance and supervision}

Lack of training and mentorship from senior researchers had been cited too as one of the major challenges that facing scientific research. It was indicated that most of the potential mentors and senior researchers are too busy with their work and have little time for junior researchers. This lack of training may lead to lack of confidence to take-up new studies.

\section{Organizational obstacles and difficulties for obtaining data}

Data collection is not always an easy job, and most often secrecy takes place. Policy-makers and stakeholders usually unwilling or don't want to make much information at public level. Therefore, absence of reliable sources can make the process of research writing difficult.

\section{Discussion}

This work was an attempt to give an overview of some challenges that facing scientific research. Four types of challenges had been concluded in the current study. One of these challenges is resources and research facilities problems. Similarly, Kumwenda et al, Dunya and Jamal reported that the most challenges that cited by their surveys' respondents include scarcity of resources. They argue that most of Arab universities and academic institutions are meant for education and not for scientific research.5,6 Additionally, Mahmoud believes that investors need to be encouraged to invest in scientific research that would lead to better results on their industries and communities. ${ }^{7}$

Regarding the motivation and incentives challenges that had been reported in our study, it has been noticed that motivation is one of the important elements that can encourage researchers to conduct more researches. This 
obtained fact was supported by Chen, Gupta and Hoshower. ${ }^{8}$ In the same line, Jindal and Jonathan highlighted that motivation and incentives are crucial in encouraging young researchers. ${ }^{9}$ Moreover, two previous studies by Tien found that extrinsic motivation and promotion perspectives have a significant influence on research productivity. ${ }^{10,11}$

The current study revealed that lack of training, guidance and supervision can be one of the major challenges that encounter scientific research in many areas globally, which goes with what was reported by Akyurek and Afacan who stated that there is need for senior researchers to start engaging young scientists at every stage and not only when they want to generate data. ${ }^{12}$ Pearson and Kayrooz believe that lack of training and mentorship from senior researchers had been cited as one of the major challenges that facing scientific research. ${ }^{13}$

Concerning organizational obstacles and difficulties for obtaining data, this study shows that the process collecting data was not an easy job. Many researchers suffer from getting permissions from stakeholders and in particular from private sectors, while others may give vague and inadequate information, which can affect the researchers' results negatively. This is well in line with previous studies reported that the field workers were generally more cautious, and to some extent reflecting a continuing concerns about the need for local benefits of data sharing. Therefore, they remained consistently negative towards data sharing based on concerns about potential for misuse. ${ }^{14,15,16}$

\section{Conclusion and recommendation}

Considering the result of the research, the major challenges that facing research include scarcity of resources and funding, lack of motivation, lack of training, guidance and supervision, organizational obstacles and difficulties of collecting data which accompanied by low demand for research by policymakers. Research capacity building courses, collaboration and networking opportunities are urgently needed. Additionally, it was suggested that the two key ways to encourage strong research studies would involve rethinking the rewards system and building more transparency into the research process, beside to get ways to increase donors or grants for running the researches' costs.

Motivation and effective learning and training processes are also beneficial and important issues to be considered to equip future researchers with the necessary research skills. Importantly, inherent uncertainties in data sharing (about what data will be shared, with whom, for what purpose and when) can be overcome by building trust in relationships within and between stakeholder groups was a key component of ethical practice.

\section{Competing interest}

Authors would like to declare that they have no any conflict or competing interests.

\section{Funding}

No any fund obtained from anywhere for the current work.

\section{Authors' contributions}

All authors contributed in literature review, collecting data from different sources, interpretation. Moreover, all of authors read and approved the final manuscript and agreed to be published

\section{References}

[1] Science. Information for authors: Data and materials availability. Online information; cited December $16^{\text {th }}$, 2018 from the following site: http://www.sciencemag.org/site/feature/contribinfo/ prep/gen.info.xhtml\#dataavail.

[2] Benatar SR. and Singer PA. Responsibilities in international research: a new look revisited. Journal of medical ethics. 2010; 36(4): 194 -7.

[3] Gilson L. trust and the development of health care as a social institution. Social science and medicine. 2005; 56(7): $1453-68$.

[4] Liverani M., Teng S, Le Ms. and Coker R. Sharing public health data and information across borders: Lessons from Southeast Asia. Global Health. 2018; 14(1): 94.

[5] Kumwenda S, Niang H. et al. Challenges facing young African scientists in their research careers: A qualitative exploratory study. Malawi Medical Journal. 2017; 29(1): 1 - 4 .

[6] Dunya Ahmed, Jamal Albuarki. Review of the challenges of Scientific Research in the Arab World and its influence on Inspiration Driven Economy. International Journal of Inspiration and Resilience economy. 2017; 1(1): $28-34$.

[7] Mahmoud KW. A study on the Role of Research Centers in the Arab World, Arab Center for Research and Policy Studies, 2013. Online information cited December 17th, 2018 from the following site: www.sapub.org/global/showpaperpdf.aspx?doi=10.59 23/j.ijire.20170101.04.

[8] Chen Y., Gupta A. and Hoshower L. Factors That Motivate Business faculty to conduct Research: An expectancy Theory Analysis. Journal of education for Business 2006; 81(4): 179 - 89.

[9] Jindal D. and Jonathan B. Motivation of scientists in a government research institute: Scientists' perceptions and the role of managemen. Management decision. 2006; 44(10): 1325 - 1343.

[10] Tien F. To What Degree Does The Desire For Promotion Motivate Faculty To perform Research? Testing The Expectancy Theory; Research in Higher education. 2000; 41(6): $723-51$.

[11] Tien F. F. What Kinds of Faculty Are Motivated to Perform research by the Desire for Promotion? Higher Education. 2008; 55(1): 17 - 32.

[12] Akyurek E. and Afacan 0. Problems Encountered During the Scientific Research Process in Graduate Education: The institute of Educational science. Canadian Center of Science and Education. 2018; 8(2): $47-57$.

[13] Pearson M. and Kayrooz C. Enabling Critical reflection and research Supervisory Practice. International Journal for academic development. 2004; 9(1): 1819.

[14] Pisani E. and AbouZahr C. Sharing health data: Good intentions are not enough. Bulletin of the World Health Organization. 2010; 88(6): $462-6$.

[15] Lessing A. and Schulze S. Postgraduate Supervision and Academic Support: Students' Perceptions. South African Journal of Higher Education. 2002; 16(2): 139 149.

[16] Sankoh O. and Ijsselmuiden C. Sharing research data to improve public health; A perspective from the global South. Lancet. 2011; 378(9789): $401-2$. 